Article

\title{
The Inclusion Conundrum: A Critical Account of Youth and Gender Issues Within and Beyond Sport for Development and Peace Interventions
}

\author{
Holly Collison ${ }^{1, *}$, Simon Darnell ${ }^{2}$, Richard Giulianotti ${ }^{1,3}$ and P. David Howe ${ }^{1}$ \\ ${ }^{1}$ School of Sport, Exercise and Health Sciences, Loughborough University, Loughborough, LE11 3TU, UK; \\ E-Mails: h.collison@lboro.ac.uk (H.C.), r.giulianotti@lboro.ac.uk (R.G.), p.d.howe@lboro.ac.uk (P.D.H.) \\ 2 Faculty of Kinesiology and Physical Education, University of Toronto, Toronto, ON M5S 2W6, Canada; \\ E-Mail: simon.darnell@utoronto.ca \\ ${ }^{3}$ Faculty of Humanities, Sports and Educational Science, University College of Southeast Norway, 3800 Bo, Norway \\ * Corresponding author
}

Submitted: 30 January 2017 | Accepted: 20 April 2017 | Published: 29 June 2017

\begin{abstract}
The sport for development and peace (SDP) sector is made up of various development-focused policies and programs that seek to engage, stabilise, empower and create social and economic change. SDP projects, most often run by nongovernmental organisations (NGOs), have been implemented in regions enduring physical conflicts, health pandemics, major gender divisions and other social crises that have a great impact on youth. In this context, sport has been accorded the difficult task of facilitating greater access for marginal, vulnerable or community groups whilst positively contributing to the attainment of diverse development objectives. While the 'where' and 'why' of SDP has been largely accounted for, the attention in this article is on the 'who' of SDP in relation to the notion of inclusion. Drawing on extensive research conducted in Jamaica, Kosovo, Rwanda and Sri Lanka, the idea of SDP as an inclusionary practice is critically investigated. While SDP may 'give voice' to participants, especially to individuals with athletic ability or sporting interests, the extent to which this creates social contexts that are fundamentally inclusive remains open to discussion. In this sense, while targeting populations, groups or individuals remains an attractive strategy to achieve specific goals, for example youth empowerment or gender equality, empirical assessments complicate the presumption that SDP programming leads to inclusion, particularly at a larger societal level. The article considers a matrix of inclusion criteria, potential outcomes, and the tensions arising between targeted SDP programming and the often-exclusionary dimensions of sport more broadly, with a focus on youth and gender issues.
\end{abstract}

\section{Keywords}

gender; NGOs; sport for development and peace; volunteers; youth

\section{Issue}

This article is part of the issue "Sport for Social Inclusion: Questioning Policy, Practice and Research", edited by Reinhard Haudenhuyse (Vrije Universiteit Brussel, Belgium).

(C) 2017 by the authors; licensee Cogitatio (Lisbon, Portugal). This article is licensed under a Creative Commons Attribution 4.0 International License (CC BY).

\section{Introduction}

The United Nations Office for Sport for Development and Peace (UNOSDP) has been very clear on their priorities and development mandate. Wilfried Lemke, United Nations (UN) Special Advisor on Sport for Development and Peace (SDP) has stated on numerous occasions his ambitions to use sport as a vehicle to address conflict resolution, gender equality, the development of Africa, in- clusion of persons with disabilities, and youth development (Peace and Sport, 2016). Social inclusion is central to such goals and has been strongly aligned to the newly established UN Sustainable Development Goals (SDGs). The same connections to sport have been made by fellow UN offices including the UN Educational, Scientific and Cultural Organization (UNESCO); Irina Bokova, Director General of UNESCO, recently stated that "Sport is a powerful vehicle for social inclusion, gender equality and 
youth empowerment, with benefits that are felt far beyond the stadiums" (United Nations, 2016). It is from this level of advocacy that large numbers of NGOs, sports federations, national governments, charitable organisations and local groups adopt sports based programming to achieve their aims. The SDP movement (Beutler, 2008; Kidd, 2008) has thus evolved over the last fifteen years and has become a recognised sector at both the policy level and for those who focus on achieving stability, peace, education and inclusion within post-conflict and developing nations.

The idea of inclusion and sport can be aligned to the conceptual lens provided within the notion of sport and social capital. The social significance of inclusion and sport and indeed social capital is connected to social networks, civic norms, social integration, community structures and civic participation (see Nicholson \& Hoye, 2008). Referring to Donnelly (1996) and Freiler (2001), Bailey $(2005$, p. 76$)$ provides a series of connected dimensions of social inclusion:

Spatial: Social inclusion related to proximity and the closing of social and economic distances.

Relational: Social inclusion is defined in terms of a sense of belonging and acceptance.

Functional: Social inclusion relates to the enhancement of knowledge, skills and understandings.

Power: Social inclusion assumes a change in the locus of control.

The concept of social inclusion can therefore be deconstructed by a series of social, economic, cultural and emotional dimensions. Such dimensions will now be demonstrated via an empirical account of SDP operating within 4 research sites. This article examines differing models of SDP in relation to social inclusion and reflects upon the outcomes and challenges connected to youth and gender. The roles participants adopt as athletes and volunteers and the socio-cultural identities of participants with regards to ethnicity, crime and violence, and social status and ageing will be discussed. This account empirically highlights several challenges central to the concept of inclusion within SDP programming and participation. Many of these challenges are known to both academics and practitioners however, the purpose of this article is to empirically examine such barriers that threaten the attainment of diversity in SDP. This article should be considered as an empirically driven account that documents and contextualises such challenges, its purpose is not to guide practitioners but to demonstrate wide ranging issues.

\section{Methods}

The article draws upon research undertaken by the authors as part of a comparative, transnational investi- gation of the SDP sector. Prior to fieldwork full ethical clearance was granted by the funder and our academic institutions internal ethics committees. All organisations, individuals and participants were fully informed of our projects objectives and we provided additional information via the projects website and pamphlet. Fieldwork was conducted in Jamaica, Kosovo, Rwanda and Sri Lanka $^{1}$ and broadly focused on three substantive areas of SDP programming: the promotion and securing of human rights, the rights and needs of people with disabilities, and the mobilization of sport towards peacebuilding and conflict resolution. Each researcher made a minimum of 2 fieldwork trips to their allocated location(s), a minimum of 4 weeks was spent in total in each research site.

The majority of data was collected through ethnographic fieldwork, deploying the classic qualitative research methods of participant observation, semistructured and focus group interviews (Eriksen, 2001; Van Maanen, 2011). The majority of focus group sessions involved the participants of SDP projects, this was deemed appropriate when spending time with predominantly young populations. Focus group sessions were not always planned, in some of our locations we were invited to conferences, staff meetings or official offices and focus group interviews organically occurred. We deployed numerous methodological approaches on the ground, in one location we were able to participate fully in the delivery of an SDP programming via a volunteer role, in another location we were asked to adopt a consultancy role to develop new ideas and this allowed for enhanced access to both programming and operational spaces. As academics with knowledge and experience of SDP we could apply our skills if requested whilst simultaneously demonstrating our desires to gain a better understanding of the environments in which we were located. At the same time, the limits to our local knowledge and customs were sometimes revealed, to the amusement of our study groups. In this sense, our research was inspired by Eriksen who has stated, "No matter which role one takes on in the field-most ethnographers are probably partly expert, partly clown" (2001, p. 25). Our abilities in the field to gain our own sense of inclusion depended on our abilities to balance both roles as expert and researcher.

Within our varying methodological pursuits as interviewers, observers, volunteers, coaches and experts, we considered SDP from multiple organizational and social layers. We observed and interviewed participant populations, NGO personnel, implementers involved in trans-national partnerships, local and foreign volunteers, sports coaches and ministerial officials and policy makers. We did not limit ourselves in the field and allowed the research to organically evolve in each location (see Collison, Giulianotti, Howe, \& Darnell, 2016). We estimate that a total of 100 formal interviews were

\footnotetext{
${ }^{1}$ All of the research sites were selected based upon SDP activity in relation to the project focuses and their national identities as either post-conflict, reporting high levels of urban violence or classed as 'developing'.
} 
conducted, ${ }^{2}$ in addition to participant observations and informal dialogue exchange. The pursuit of comparative data analysis has been a continuous task for the research team. Standardized interview questions were agreed prior to field visits and this allowed for consistency and direct comparative analysis, however, all of the locations provided methodological contrasts, cultural diversity and broadly speaking contrasting priorities, challenges and approaches. Therefore, the process of data analysis has been a significant task. Researchers produced a fieldwork report after each visit, the researchers communicate virtually on a regular basis to discuss specific topics and share their experiences and insights, the research group also meet for specific data analysis meetings. This has been a process of continuous dialogue and analysis that has evolved over a 24month period. For this article, we draw upon our experiences within each of these locations and consider the often-contradictory strategies for targeting specific populations within SDP programming and their effects on social inclusion.

\section{Youth and Gender: The Need for Clarification}

SDP is driven by the idea that sport can socially benefit the lives of the poor, vulnerable, volatile and those who lack opportunities for social, formal and health education. Due to such focuses, most NGOs, local groups and stakeholders align their programming to specific social goals for specific populations. The process of targeting specific groups then brings into question the idea of social inclusion within and beyond the boundaries of SDP. Youth and girls and women are two of the primary targets for SDP and are central to many of the SDGs as well as the goals of many developing and post-conflict nations. Although girls and young women may be considered part of the youth category and indeed intersect, the literature review which follows directs the reader to a social definition of youth-hood and one which considers the term as almost exclusively male, therefore provoking the need to consider youth and girls and women as two separate social identities. This article will consider male youth and girls and women in isolation to demonstrate differing socio-cultural positions, experiences and access to SDP programming. Before our empirical commentary, it is important to consider the potentially problematic terms of youth and gender.

The term youth is highly contested in two distinct ways, first due to the tension between chronological ageing and the process of maturation as gained through cultural systems and social pathways (Honwana, 2012). Many scholars who have considered youth identity and youth cultures present diverse discussions relating to social systems, culture, traditional rites of passage, economy, national security, politics, institutional structures, law and customs to name but a few (Durham, 2000;
Evans-Pritchard, 1969). In line with Bayart's (1993) theorisation, generational categories such as youth are part of a struggle for influence, power and authority within almost every society. Therefore, the consideration of youth raises predicaments, tensions and contrasting ideas connected to identity, membership and social inclusion and mobility. As a result, a social definition of youth aligning to specific cultural contexts is more appropriate and insightful than broad age-based indicators. Second, youth tends to present itself as a masculine term; Bucholtz considers "youth culture to be a male preserve by definition and the primary purpose of such terminology is to work out issues of masculinity" (2002, p. 537; Comaroff \& Comaroff, 2005). There is a strong link between the fragile nature of young men unable to acquire power or agency which is defined through their youth status. Masculinity therefore is a source of opportunity to assert power which derives from the body and not social mobility (Groes-Green, 2009). With these important distinctions in place we can proceed with the stance that youth is a complex social category or a life phase which tends to describe and position males most often.

As our contextual and empirical understandings of youth developed within our research locations, the notion of gender and its position within SDP raised many questions. If the consideration of youth centred around issues of masculinity and was dominated by male populations, did gender related goals and practices refer directly to women? And how was this managed within SDP environments and beyond? Saavedra observes that "In the world of sport-in-development, 'gender' is usually only invoked when referring to the involvement of girls and women" (2012, p. 128). Acknowledging that sport is engulfed in gendered dimensions is not a new claim, however. When considering the everyday workings and norms of the SDP sector, this presents a need for deeper thought and enquiry. Kay claims, "Sport is a prime site to challenge gender ideology, and it is therefore a particularly valuable area for encouraging involvement by the most disempowered women" (quoted in Collins \& Kay, 2003, p. 97). As with youth, there is a need to adopt a commitment to interpreting deeper understandings through the lens of local populations and their social structures. Gender dimensions and the participation of women requires an understanding of culturally defined social processes, power structures, local politics and cultural norms relating to education, employment and relationships (Brady, 1998). Given these issues, the experiences of women and girls has become an important topic within several case studies of SDP (Chawansky \& Schlenker, 2015; Hayhurst, 2013; Jeanes \& Magee, 2013). Such investigations have enabled nuanced and clearer understandings of the role and potential of women and girls to effect change and challenge norms that may restrict access and acceptance within social structures and educational pathways. Fixed narratives of specific groups

\footnotetext{
2 The project officially ends in June 2017, the research team continue to analyse data and pursue comparative analysis. Therefore, the authors of this article are still collating interview data and are at this time unable to provide an accurate numerical break down of interviews given within each location.
} 
therefore need to be challenged and this becomes especially important when examining the 'who' of SDP and its inclusionary effects. This literature review highlights that although girls and young women fall into the youth category, socially and empirically there are distinct social definitions that isolate girls and women and male youth populations. We now turn to examples of practice, approach and the management of SDP programs that explore the complexities of social inclusion within SDP.

\section{Sri Lanka: Athletes}

Eight weeks of fieldwork was conducted in Sri Lanka during two in-country visits between January and October of 2015. One NGO was the central feature of the fieldwork, this was due to the scale of their activities throughout the country and the diversity of sports used within their approach. The organization advocated for numerous models of delivery inclusive of the development of athletes, competitive pathways, elite coaching programs delivered by international guests, supporting school activities and hosting an annual national cricket tournament with the focus of ethnic and regional integration. The research methodology incorporated formal interviews, participant observations, focus group interviews with participants and coaches and the delivery of netball coaching sessions as a strategy to integrate with the women and girls who participated in the program.

In Sri Lanka, the backdrop to many NGO programmes is thirty years of ethnic division, conflict, social tension and the economic and infrastructure disparity between rural and urban communities (Moorcraft, 2012). One NGO we engaged with based its identity on empowering rural communities and villages. Despite the diverse education, skills training, health facilities and infrastructure support the organisation offered, it was its sporting agenda that dominated many of their large events, drew international guests and attracted donor support. Youth and girls were the primary participants of their SDP projects which focused on cricket and netball, but badminton, chess, karate, table tennis, volleyball and swimming were offered as alternative sporting pursuits. Sport took on two distinct roles, firstly as a competitive structure that focused on skill development, competition and performance. Secondly, sport was used as a tool to develop practical life skills like swimming, and personal development skills like leadership, communication and engaging with others from different regions, ethnicities and religions. The national cricket team was a source of evidence of how sport can be an example of an institution that operates in the absence of ethnic and religious prejudice within Sri Lanka. Founders of the organisation described sport as the driving force behind much of what they had achieved and acquired, and it was the process of developing athletes that provided much prestige and awareness of the work they were doing.

Cricket was the sport par excellence within the NGO and its programming structures reflected a club system with participation age bands of U13, U15, U17 through to senior male and female teams. Due to the ethnic spatial divisions in Sri Lanka, the level of access available to differing ethnic populations was largely based on the location of the SDP event or activity. The organization's impressive facilities were based in the south which is predominantly Sinhalese, yet there were examples of talented cricketers from the North, occupied by a majority Tamil population, who had been given the opportunity to join the organization's teams in the south. From this it is clear that SDP gave athletes in Sri Lanka the opportunity to be included in the more advanced club structures being implemented by a national NGO. Athletes certainly dominated the sporting spaces and this was visible through the coaching regimes, the professional way they trained, the emphasis placed on performance and the openness regarding expectations to win and progress through competitive pathways. This approach to sport within the organisation was evident both through the practice of cricket and netball. As with the boys and the smaller number of girls who played cricket, the girls netball team was also expected to perform, and individuals were expected to be selected during national trials.

Athletes were the dominant population given opportunities by this NGO in Sri Lanka, and this was reflective of the approach to cricket and to a lesser extent netball within the country. Those who showed interest but were less skilled could have training opportunities but the focus was the performance and this was potentially ostracising to many. Within this performance structure, age was an indicator for placing players; social maturation was never a consideration in their practices but neither were the social realities of their lives outside of SDP. Poverty, racial divide or social challenges were not openly discussed and were not part of the sporting programme. When asked why this was, one employee responded "it's like driving a car and looking behind you, you'll crash. We don't discuss the past we focus on the future". This philosophy was evident throughout their programming; by playing sport athletes would develop not only their skills but the personal characteristics associated with good sportsmanship, fair play and a peaceful existence.

Those who succeeded were aware of their potential for economic mobility, many of the coaches and the foundations trustees were former elite cricketers or involved in the business management of elite cricket. Such role models highlighted the gains to be made. Those who were not athletes would need to discover such personal and economic development elsewhere. There is a clear connection here to be made using the afore mentioned Freiler (2001) dimensions of social inclusion, in the Sri Lankan context, economic mobility (spatial), belonging to a team and social acceptance as a potential elite or successful athlete (rational), may lead to both a change in the locus of control and therefore power which results in social mobility and inclusion within society. For the few who may achieve the goal of professionalism, this model of SDP serves a significant purpose, however this may be 
at the detriment of those who do not reach such levels or those who are excluded from the pathway altogether. Participation maybe intended to develop personal development characteristics broadly associated with sport but achievement and financial potential are valued and more closely connected to inclusion within society and within SDP models within Sri Lanka.

\section{Kosovo: Volunteers and Ethnicity}

Kosovo is a post-conflict, contested state located in the western Balkan region of Europe. In Kosovo, there are two main SDP NGOs which have different goals, structures, modes of delivery, and 'ways into' their locations of activity. One NGO was exclusively focused on promoting stronger cross-cultural relations and understanding; the other was focused on this goal, as well as others, such as promoting the social inclusion of girls, people with disabilities, and those with substance addictions. The two NGOs have different strategies, which include running multi-game activities nationally throughout the year and hosting large-scale football events for children mainly during the summer. 'Youth' within the context of Kosovo might refer more accurately to teenage participants on intervention programmes, and the volunteers who take on roles of 'animators' or 'coaches' during the activities. Both NGOs have local volunteer structures in place. For one NGO, the volunteers are relatively young (usually aged around 15-24); tend to reflect the ethnic composition of their local area; feature a good mix of males and females; and, have almost always entered initially as participants before moving on to become volunteers.

A key issue was mobilizing young people to become civic actors and leaders. One long-term NGO official highlighted to us that making young people more socially active in community and public activities was an important result for them. An issue to bear in mind is that both NGOs relied substantially on local youth populations as volunteers to put on sessions and to do the day to day work. In one NGO, most of these volunteers were young, motivated, and either looking to or having reasonable qualifications that in Western European contexts would otherwise have secured them with reliable white-collar employment. The economic situation is much more problematic with high levels of poverty, unemployment and visa restrictions on travelling into the European Union. In the other NGO, volunteers tended to be already involved with sport clubs which delivered the sessions. Local NGO officials and volunteers recognized that there were clear limits on the extent to which volunteers could be asked to conduct activities. We were present when one international NGO official, who had flown in to visit and to observe activities in Kosovo, suggested to local volunteers that more sessions could be put on to keep unemployed young people entertained; a local volunteer responded that these activities were already taking up a good deal of the free and holiday time, as well as some money, that was available to the volunteers.
The young volunteers that we spoke with largely emphasized the same factors behind their participation. These included their dual enjoyment, of working with children, and of the sports and games that they were leading. They also highlighted the new skills and capabilities that they learned from the NGOs; in some cases, such as physical education students or those looking to set up their own NGOs, these skills were viewed as being of direct benefit for their education or work. At the same time, several of these young people emphasized the difficulty of translating these employability skills into secure, long-term employment, due to the economic weaknesses of Kosovo and the strong belief that many jobs and educational openings were filled through 'social capital' ties including corrupt practices.

As with the Sri Lankan example, in Kosovo ethnicity is a significant factor in terms of SDP participation opportunities and social inclusion outside of sporting space. Participants in the activities of both NGOs largely reflected the ethnic or national make-up of the local populations, mainly divided along Albanian and Serbian lines. Thus, activities in mainly Albanian municipalities attracted mainly Albanian participants, while the same applied to sessions in Serbian enclaves. Despite their inter-cultural focus, both NGOs reported that it could be difficult to draw one group across into the demarcated spaces of the other. The risk in Kosovo inevitably centred on the post-conflict situation and relations between Albanians, Serbs and other small minorities notably Roma. So, whilst sport was positioned as a tool to challenge ethnic divisions within Kosovo, the restrictions in practice placed upon location, language, embedded prejudice and capacity often brought the notion of social inclusion into question.

\section{Jamaica: Citizenship and Creating Safe Spaces}

Fieldwork was undertaken in Kingston in May of 2015 and 2016, with two weeks spent in-country on each occasion. Ethnographic data was collected primarily through observations and interviews; focus groups with program participants were conducted where appropriate. Over the course of the two field visits, some 40 interviews were conducted as well as three focus groups. In addition, a series of observations were made of SDP activity. Four organizations based in Kingston constituted the bulk of the research focus. We made initial contact with these organizations through international SDP funders and policy makers. The Kingston-based organizations were nongovernmental, and operating with charitable supportboth financial and curricular-from corporate foundations or international SDP organizations.

In Jamaica, the issue of urban violence, crime and gun violence is the foundation for many locally organized community projects, as well as formal international NGOs working with a sports mandate. The concept of using sport as a tool for education, social rehabilitation and the creation of safe spaces is not a new movement or phenomenon in Jamaica but in recent years the sec- 
tor had grown due to the possibilities brought by international interest, access to funds and the potential to create platforms to share best practice models and build sustainable programs. Arguably, sport for development in Jamaica is used as a tool for both prevention and cure within the context of crime and violence. The approach of two separate SDP organizations demonstrates this whilst also highlighting those that fit into the identities of vulnerable, potentially volatile or as Honwana and De Boeck claim 'Makers and Breakers' of a society (2005).

In a case study report of crime in Jamaica it was reported that " $99 \%$ of murders were committed by males between 1997-2005, and over half of these were aged 25 years or younger" (Gray, 2007, p. 17). These statistics align to the feelings on the ground that young males or youth are the perpetrators or most likely to participate in crime and continue the cycles of violence within Kingston. One approach to this societal issue was the construction of citizenship amongst youth through sport and in particular football. The notion of community and indeed service to ones' community is important to the establishment of this organization that was founded upon Christian ideals. With a legacy of political violence and social tension, the concept of community is one which provides significant appeal to local populations. Through the participation of football, youth players are encouraged to become citizens who think beyond their individual needs, both as team members but also as members of their community. The leader of the organization places great emphasis on the mental, spiritual and physical development gains to be had by participating in football and being part of the organization. Through this approach, citizenship and the notion of community is in some ways symbolically constructed through participation but also demonstrated through their commitment to their team and the area in which they live. Whether such values are carried from the playing field is questionable but the players willingly separate themselves from such behaviors via the organization and football.

In line with the urban crime figures in Jamaica, women and children are far more likely to become victims of criminality and exposed to violence. One organization in Kingston prioritized the needs of children who had been identified and selected as vulnerable. Sport was part of the strategy attached to creating a safe space that was removed from the violent realities of the society around them. As such, sport had a significant pull and represented an activity that was fun, operated in the absence of structure and allowed for care free, safe physical pursuits. This form of selection and referral system could not allow for broader inclusion criteria's when the objective was focused towards nurturing, protecting and building a sense of resilience amongst a population identified as the most at risk. SDP in this context operated with the intention of insulating, and therefore also excluding, due to the fragile and volatile nature of the society it operated within.

These examples demonstrate a gender dynamic to the approach and targeted recipient population of SDP programs. This reflects both the social conditions on the ground and the gender norms attached to crime and violence. SDP and sport has for many years had a role to play in Kingston when attempting to tackle cycles of violence and indeed its consequences. The SDP sector in Jamaica highlights the role aligned to sport for both prevention and cure and the various forms that selection and targeting can take to enroll those deemed either vulnerable or volatile. The lack of social inclusion in this context is quite deliberate and part of the overarching strategy to manage safe spaces and or encourage the development of youths as citizens.

\section{Rwanda: Where Are the Girls?}

Rwanda's tragic history of genocide sets the foundation for many social development projects and NGO curriculums that have emerged over the last two decades (Uvin, 1998). Whilst genocide provides a historical context, many NGOs focus on the issues of poverty, gender equity, health and personal development skills. Such development themes fit within the national agenda for progress and stability and importantly are supported by the state. In 2015, a member of the research team volunteered with an international SDP organization that implemented a multi themed curriculum in partnership with a local Rwandan NGO, and that specifically focused on football as a tool for social change. Both organizations positioned gender equity and female participation as one of their priorities. The question that lingered throughout the time on the football fields was, "where are the girls?"

Between July 2015 and June 2016, 6 weeks of fieldwork was conducted within 3 districts of Rwanda. Initial contact prior to fieldwork was made with an international 'Sport for Social Impact' organization who implemented their model of SDP with local organizations and groups via a curriculum. It was agreed that a volunteer role would be adopted by the researcher for the purpose of integration and following the dynamic and participatory ethos of the organization. Data collected was gained through the lived experience of implementing a SDP program, focus group interviews with participants, participant's observations, staff meetings prior to and post on-the-field sessions and formal interviews with local stakeholders. For both the local and international organizations, targeting or selecting specific groups or populations was not part of the participation criteria. Access to the 'Football for Social Impact' programme was free, open and welcoming to all. Naturally many of those who attended had an interest in football as players, coaches, teachers or those that just enjoyed having the opportunity to be within a football environment. There were no age or social barriers based on participation and children, youths, adults, elders, and women were all encouraged to join the sessions. Inclusion was a priority during this four-week national SDP program. The approach to the gender equity section of the curriculum was one of dynamic dialogue and practical demonstrations through 
football, and many of the conditioned games sparked passionate debates. A favourite was the introduction of games focused around the skill set of former Nigerian female footballer Perpetua Nkwocha; the idea of replicating the skills of a female footballer was uncomfortable for some and during one discussion she was compared to 'looking like and playing like a man'. This in many ways was the reaction that the implementers were seeking as it offered the opportunity to challenge such views and draw a debate amongst the group. This kind of debate centred around female athletes and provided insights into the contextual gender norms experienced within the location, and would then facilitate further dialogue that could be challenged.

The relative absence of girls and women within the program was visible. The women who did attend were very proactive in their communities as coaches and the majority were skilled players but had few opportunities to play due to the male dominated competitive leagues. During focus group sessions with the recipients of the program, the issue of low numbers of girls and women was discussed. The responses given were consistent amongst the groups and indeed the same during interviews with high level sports officials. Body image was a significant concern both in terms of developing "masculine body types" as well as the concern to "not be able to attract a husband if she is playing like a man". In addition to this, young girls and women had specific domestic roles to fulfil from a young age and this was also given as a reason why many young girls enjoy playing sports and exercising at school despite a significant drop off after graduating from high school. Some of the girls also recognised the lack of female sporting role models and the fact that "there is no history of us succeeding in sport, now that Team Rwanda and the cyclists are doing well more boys want to ride to be like them but the girls do not try because no girls are there already".

The lack of legacy of female sport in Rwanda is clearly a hurdle to the participation levels within SDP programming (Meier \& Saavedra, 2009). The dominant male groups involved were quick to recognise the role of women in powerful positions in government and the strength of the women in their homes, but when it came to sport they felt that girls and women generally were not interested, were needed elsewhere or were 'lazy'. Their opinions of female athletes were often negative and highlighted the challenges and boundaries faced by those who may well have had a desire to participate. In the absence of equally mixed groups, those who participated were clearly challenged in their views and their norms were questioned. So, despite the inclusionary ethos of the SDP program, the challenge was embedded in the notion of sport and participation away from the confines of SDP.

\section{Discussion}

The purpose of this article has been to contextualise and empirically examine a number of approaches and chal- lenges within the implementation of SDP projects within diverse national contexts. Youth and women have been at the centre of this analysis and the case studies have supported the initial statements that youth and SDP have complex gender dimensions. Youth are often described as marginal, passive, stuck or waiting within their social position (Sommers, 2012; Vigh, 2006). Yet for some, their roles and progression within SDP as athletes (Sri Lanka), volunteers and young leaders (Kosovo) show the dynamic nature of youth within differing social positions. Youth are the dominant recipient population of SDP and this research has highlighted the relative absence of girls and women within SDP spaces in some of our locations. This is reflective of either the cultural and social norms on the ground that create boundaries for access or the notion of sport as a masculine construct that crosses over into development practices. The representation of women in SDP has been present at the operational levels or through the narratives of those who are the exception, making their experiences within and beyond SDP all the more impressive. The female coaches developing their social impact strategies in Rwanda were quick to recognise their struggles for young girls to participate, "In Rwanda, girls like to play but they have no older girls to look to. When they get a little bit older they do other things, or stay in the home to help family, even worse they think boys will not like them if they play sport. Girls and women are left behind, there are too few of us". For women, social inclusion through SDP still has some way to go; we might suggest that it is through the lens of local populations and the work of local leaders that this may be challenged.

This article has demonstrated that at times the initial hurdle for local populations to gain access and participate within SDP is fitting into a social, skilled or at-risk category. In this regard, the alignment between NGO strategy and the needs on the ground is crucial to the idea of inclusion, 'success' and broader impact. The case studies have highlighted the need, within specific models of SDP, to target set populations to create safe spaces and achieve specific aims. In Jamaica for example exclusion cannot lend itself to social inclusion but focused inclusion serves to protect and build resilience. In contrast, in Sri Lanka, selection based on talent and the development of athletes can be isolating to those who do not meet the standards, but participation can produce opportunities for ethnic integration and inclusion rarely seen outside of sport.

What has become clear within this contextual account are the dimensions aligned to social inclusion within differing national contexts. Referring back to Freiler (2001), the notion of social and economic distances (spatial), experiencing a sense of belonging or acceptance (rational), the enhancement of knowledge, skills, or understanding (functional) and a change in the locus of control (power), can all be aligned to the social challenges faced by youth and women and girls and highlights not only the barriers to inclusion, both within society and within SDP programmes, but the potential gains 
to be experienced through participation. The realities on the ground suggest that such dimensions of inclusion are experienced by the few and not the majority, inclusion questionably becomes an opportunity for those already with a sense of agency, the talented and the targeted.

\section{Acknowledgements}

Funding Acknowledgement: ESRC (Award Number: ES/L002191/1).

\section{Conflict of Interests}

The authors declare no conflict of interests.

\section{References}

Bailey, R. (2005). Evaluating the relationship between physical education, sport and social inclusion. Educational Review, 57(1), 71-90.

Bayart, J. F. (1993). The State in Africa: The politics of the belly. London: Longman.

Beutler, I. (2008). Sport serving development and peace: Achieving the goals of the United Nations through sport. Sport in Society, 11(4), 359-369.

Brady, M. (1998). Laying the foundation for girls' healthy futures: Can sports play a role? Studies in Family Planning, 29(1), 79-82.

Bucholtz, M. (2002). Youth and cultural practice. Annual Review of Anthropology, 31, 525-552.

Collins, M. F., \& Kay, T. (2003). Sport and social exclusion. London: Routledge.

Collison, H., Giulianotti, R., Howe, P. D., \& Darnell, S. (2016). The methodological dance: Critical reflections on conducting a cross-cultural comparative research project on 'Sport for Development and Peace'. Qualitative Research in Sport, Exercise and Health, 8(5), 413-423.

Comaroff, J., \& Comaroff, J. (2005). Reflections on youth: From the past to the postcolony. In A. Honwana \& F. De Boeck (Eds.), Makers and breakers: Children \& youth in Postcolonial Africa. Oxford: James Currey.

Donnelly, P. (1996). Approaches to social inequality in the sociology of sport. Quest, 48, 221-242.

Durham, D. (2000). Youth and the social imagination in Africa: Introductions to part $1 \& 2$. Anthropological Quarterly, 73(3), 113-120.

Eriksen, T. H. (2001). Small places, large issues. An introduction to social and cultural anthropology (2nd ed.). London: Pluto.

Evans-Pritchard, E. E. (1969). The Nuer: A description of the modes of livelihood and political institutions of a Nilotic people. New York and Oxford: Oxford University Press.

Freiler, C. (2001). From experiences of exclusion to a vision of inclusion: What needs to change? Retrieved from www.ccsd.ca/subsites/inclusion/bp/cf2.htm

Gray, S. (2007). Trends in urban crime and violence in Kingston, Jamaica. Retrieved from http://unhabitat.
org/wp-content/uploads/2008/07/GRHS.2007.Case Study.Crime_.Kingston.pdf

Groes-Green, C. (2009). Hegemonic and subordinated masculinities: Class, violence and sexual performance among young Mozambican men. Nordic Journal of African Studies, 18(4), 286-304.

Hayhurst, L. M. (2013). Girls as the 'new' agents of social change? Exploring the 'girl effect' through sport, gender and development programs in Uganda. Sociological Research Online, 18(2), 8.

Hayhurst, L. M., Kay, T., \& Chawansky, M. (Eds.). (2015). Beyond sport for development and peace: Transnational perspectives on theory, policy and practice (Vol. 53). London: Routledge.

Honwana, A. (2012). The time of youth: Work, social change, and politics in Africa. Sterling, VA: Kumarian Press.

Honwana, A., \& De Boeck, F. (2005). Makers \& breakers: Children and youth in postcolonial Africa. Oxford: James Currey.

Jeanes, R., \& Magee, J. (2013). Promoting gender empowerment through sport? Exploring the Experiences of Zambian female footballers. In Global sportfor-development (pp. 134-154). London: Palgrave Macmillan UK.

Kidd, B. (2008). A new social movement: Sport for development and peace. Sport in Society, 11(4), 370-380.

Meier, M., \& Saavedra, M. (2009). Esther Phiri and the Moutawakel effect in Zambia: An analysis of the use of female role models in sport-for-development. Sport in Society, 12(9), 1158-1176.

Moorcraft, P. L. (2012). Total destruction of the Tamil Tigers: The rare victory of Sri Lanka's long war. South Yorkshire: Pen \& Swords.

Nicholson, M., \& Hoye, R. (Eds.). (2008). Sport and social capital. Oxford: Elsevier.

Peace and Sport. (2016). Promoting the United Nations values through sport. Retrieved from http://www. peace-sport.org/opinion/promoting-the-united-na tions-values-through-sport

Saavedra, M. (2012). Dilemmas and opportunities in gender and sport-in-development. In R. Levermore \& A. Beacom (Eds.), Sport and international development. New York: Palgrave Macmillan.

Sommers, M. (2012). Stuck: Rwandan youth and the struggle for adulthood. Athens and London: The University of Georgia Press.

United Nations. (2016). Sport plays essential role in advancing 2030 development agenda. Retrieved from http://www.un.org/apps/news/story.asp?NewsID=5 3620\#.WDXqPqX77ml

Uvin, P. (1998). Aiding violence: The development enterprise in Rwanda. Kumarian Press.

Van Maanen, J. (2011). Tales of the field: On writing ethnography. London: University of Chicago Press.

Vigh, H. (2006). Social death and violent life chances. In Navigating youth-generating adulthood: Social becoming in an African context. Uppsala: Nordiska Afrikainstitutet. 


\section{About the Authors}

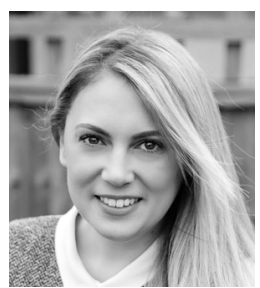

Holly Collison is a Research Associate in the School of Sport, Exercise and Health Science at Loughborough University. Holly is an Anthropologist with extensive fieldwork experience in West Africa, Rwanda and Sri Lanka. Previous research has focused on urban youth, notions of community, status and identity and post-conflict development, specifically the use of football in sport for development and peace interventions. Her book, Youth and Sport for Development and Peace: The Seduction of Football in Liberia was published in 2016 by Palgrave Macmillan.

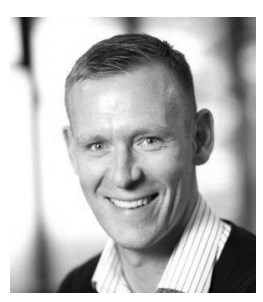

Simon C. Darnell is an Assistant Professor in the Faculty of Kinesiology and Physical Education at the University of Toronto. His research focuses on the relationship between sport and international development, the development implications of sports mega-events, and the place of social activism in the culture of sport. He is the author of Sport for Development and Peace: A Critical Sociology and coauthor of Sport and Social Movements: From the Global to the Local (both published by Bloomsbury Academic).

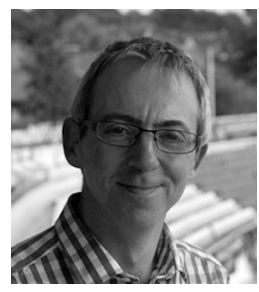

Richard Giulianotti is Professor of Sociology at Loughborough University, UK, and also Professor II at the University of Southeast Norway. His main research interests are in the fields of sport, globalization, development and peace, sport mega-events, crime and deviance, cultural identities, and qualitative methods. He is author of the books Football: A Sociology of the Global Game (1999), Sport: A Critical Sociology (2005, fully revised 2015), Ethics, Money and Sport (with A.J. Walsh, 2007), Globalization and Football (with R. Robertson, 2009), and Policing the 2012 London Olympics (with G. Armstrong and D. Hobbs, 2016).

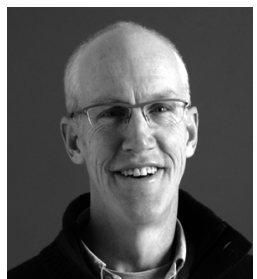

P. David Howe is Reader in the Social Anthropology of Sport in the School of Sport, Exercise and Health Sciences at Loughborough University. David is a leading figure in socio-cultural analysis of Paralympic sport and holds a visiting professorship at Katholieke Universiteit Leuven, Belgium and an adjunct Professorship at Queen's University, Canada. Trained as a medical anthropologist, he is the author of Sport, Professionalism and Pain: Ethnographies of Injury and Risk (Routledge, 2004) and The Cultural Politics of the Paralympic Movement: Through the Anthropological Lens (Routledge, 2008). 